\section{Zufriedene Teilnehmer beim 3. Greifswalder Ryck-Symposium}

Am 2. und 3. September fand in diesem Jahr das nunmehr 3. „Greifswalder Ryck-Symposium“ statt. 100 Teilnehmer, Referenten und Aussteller aus neun verschiedenen Bundesländern sowie aus Berlin und Hamburg haben wieder den Weg nach Greifswald auf sich genommen und wurden mit einer gelungenen Fortbildungsveranstaltung belohnt. Das spiegelt auch die Auswertung der Feedbackbögen wieder, die von den Teilnehmern am Ende der Veranstaltung ausgefüllt wurden.

Wie bereits in den vergangenen Jahren gab es auch in diesem Jahr an beiden Tagen wieder ein thematisch breit gefächertes Programm. Engagierte Referenten gestalteten 16 Vorträge interessant, lehrreich und kurzweilig. Besonderes Interes- se fand wie erwartet der Ultraschallvortrag von Prof. Thomas Fischer, Berlin, was zeigt, dass MTRA durchaus wissbegierig und bereit sind, sich neuen Aufgaben zu stellen. Aber auch andere Vorträge, wie z. B. der Vortrag von PD Dr. Sönke Langner,
Greifswald, über das Zusammenspiel von MTRA und Radiologe bei der Interventionellen Schlaganfalltherapie, kamen bei den Teilnehmern sehr gut an und wurden noch in den Pausen diskutiert.

Erstmalig wurden in diesem Jahr auch drei Hands-on-Workshops, vor Beginn des Vortragsprogramms am Samstag, angeboten. Die Frühaufsteher unter den Teilnehmern konnten wählen zwischen: Erste praktische Begegnung mit dem Ultraschall, Praktische Materialkunde in der Angiografie und Praktische Tipps zur Patientenumlagerung. Auch hier zeigte sich wieder das große Interesse der MTRA am Ultraschall, aber auch die anderen beiden Workshops waren ausgebucht bzw. gut besucht. 
Für die Industrieausstellung hatten in diesem Jahr sogar 14 Firmen ihre Stände im Foyer des Klinikums aufgebaut und hielten für die Teilnehmer Informationen zu ihren Produkten und Entwicklungen bereit. Sowohl die Firmen der „1. Stunde“, die uns seit drei Jahren die Treue halten, als auch die Firmen, die erstmalig beim Greifswalder Ryck-Symposium dabei waren, trugen wieder sehr zum Gelingen und zur Attraktivität der Veranstaltung bei.

Das Rahmenprogramm, ein Segeltörn auf dem Greifswalder Bodden bei bestem
Spätsommerwetter, hat beim Greifswalder Ryck-Symposium bereits Tradition und durfte schon deshalb nicht fehlen. Wieder ging es am Freitag nach dem offiziellen Programm mit dem Bus nach Kröslin zum Schiff „Weiße Düne“. Die Gäste wurden mit einem Begrüßungstrunk willkommen geheißen und machten es sich auf Deck bequem. Es wehte eine leichte Brise und wer sich beim Segelsetzten nützlich machen wollte, bekam dazu auch Gelegenheit. Ein traumhafter Sonnenuntergang, leckeres Essen an Bord und gute Gespräche in entspannter Atmo- sphäre ließen den Abend zu einem Erlebnis werden. Und als es von Bord ging, stand für einige Teilnehmer schon fest: Wir kommen wieder. - Für die Organisatoren ein schönes Kompliment.

An dieser Stelle möchte ich mich bei allen Beteiligten, insbesondere bei den Vertretern der Industrie und den Referenten, vielmals bedanken, ohne die eine erfolgreiche Veranstaltung nicht möglich gewesen wäre.

\section{Brigitte Olbrich}
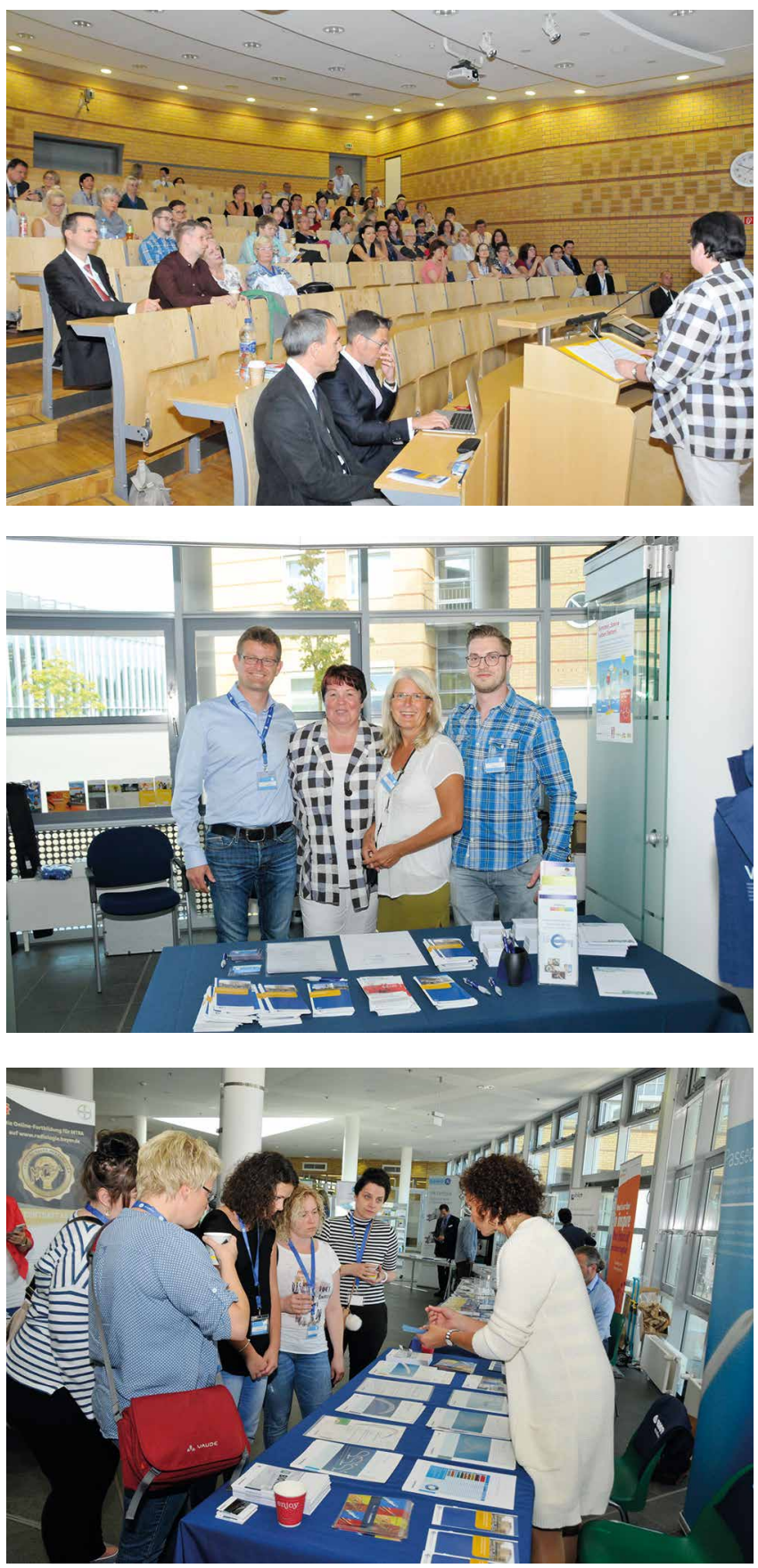
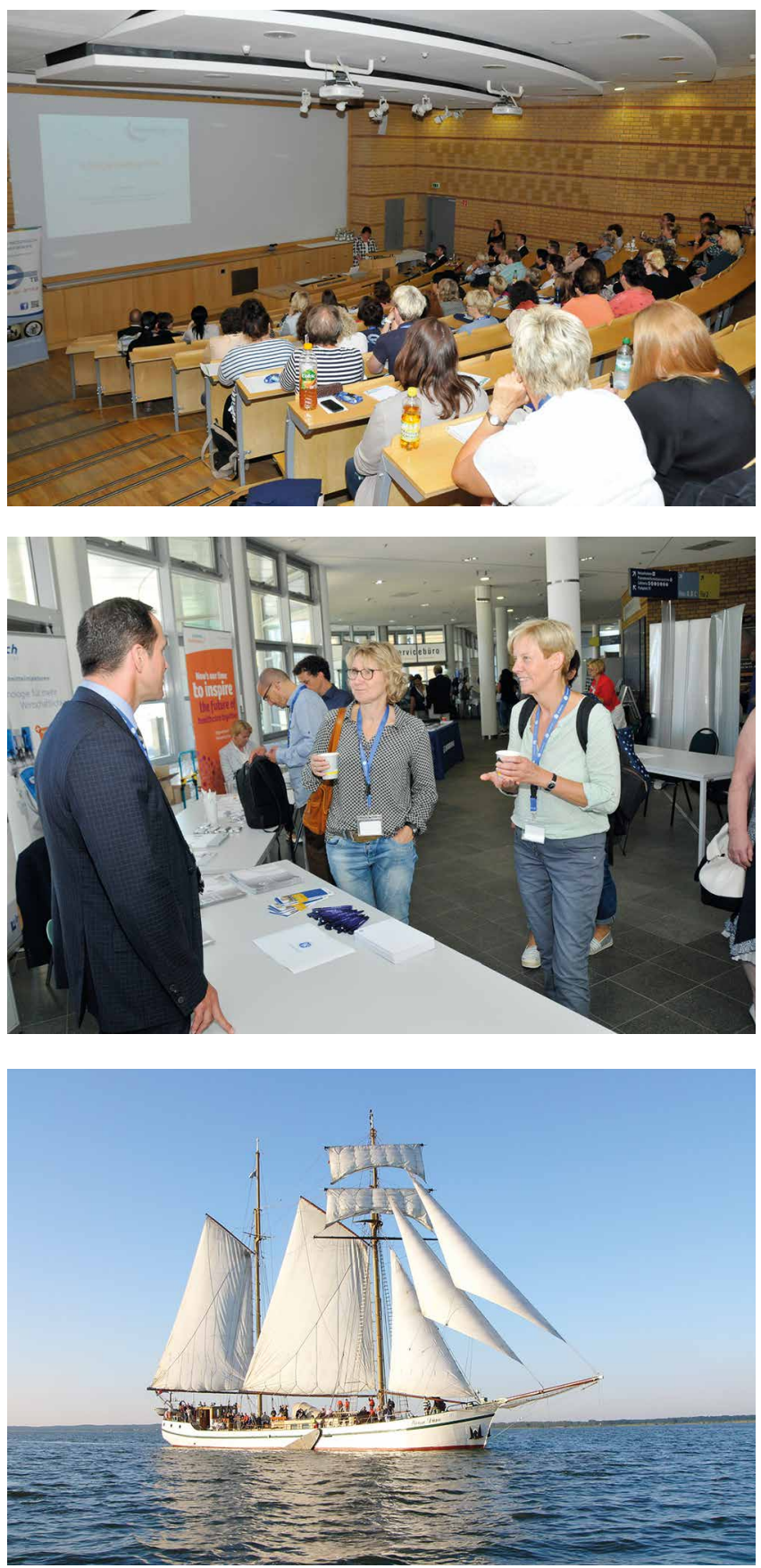